\title{
Genetic structure of ural populations of Larix sibirica Ledeb. on the base of analysis of nucleo- tide polymorphism
}

\author{
Yu. S. Vasilyeva', A. A. Zhulanov', S. V. Boronnikova', Yu. A. Yanbaev²* \\ ${ }^{1}$ Perm State National Research University, Bukireva str.-15, Perm, 614990, Russia. \\ ${ }^{2}$ Bashkir State Agrarian University, 50-letiya Oktyabrya str.-34, Ufa, 450001, Russia. \\ *Corresponding Author:Y. A. Vanbaev, E-Mail: Yanbaev_ua@mail.ru
}

\begin{abstract}
Research on the state and dynamics of the gene pool (an important natural resource that determines the potential fitness of living organisms and, ultimately, their long-term survival) becomes an important problem in the context of increased anthropogenic environmental impact. They are especially important for key species of ecosystems of a global scale importance. Larix sibirica Ledeb., which spreads from the Western Siberia to the Russian North-West, is one of such forest tree species. We identified patterns of genetic structure of populations on the example of the species'Western race on the Middle and Northern Urals. The analysis of nucleotide polymorphism of genes of ABA-inducible protein, MADS-boxtranscription factor and of 4-kumarat: COA ligase (a part of the gene) was used as a method. Evidences were obtained that a part of the populations previously formed a single large population. At the same time, populations with different gene pools were found. As a result, differences between populations within the region were more pronounced (fixation index $F_{S T}=$ $-0.021-0.260$, total haplotype diversity $H d=0.636-0.911$; nucleotide diversity $\pi=0.005-0.009$; number of mutations $\theta_{w}$ $=0.005-0.012$ ) than in other parts of the race. Causes of this phenomenon are discussed. It was concluded that the larch forests with a unique gene pool and/or high genetic diversity should be objects of population-oriented forestry and conservation.
\end{abstract}

Keywords: : Larix sibirica Ledeb., Urals, genetic structure, gene pool, populations, nucletide polymorphism

\section{Introduction}

The genus Larix Mill. includes a group of coniferous tree species of Russia which occupy wide areas from coasts of the Barents Sea to Kamchatka peninsula. Stands with their domination cover about 2.80 million square $\mathrm{km}$ ( $37 \%$ of the Russian forest area and $54 \%$ of its Siberian part) and have more than 25 billion cubic meters of timber (Martinsson and Lesinski, 2007). These estimates clearly prove a great economic, social and ecological importance of the Russian larch on the whole planet scale. Eurasian Larix sibirica Ledeb. has the largest area and spreads from the Western Siberia to the Russian North-West. Two genetic population groups revealed in the species (Semerikov and Lascoux, 2003). One of them is identified as the Eastern race (Semerikov et al., 2007). It represents forests with domination of the larch in the eastern part of the Western Siberia and all the Eastern Siberia. The Western race, named also earlier as L. sukaczewii Dyl. (Dylis, 1947), occupies especially extensive areas, including the European part of Russia, the Urals and a part of West Siberian lowlands. The race differs from the eastern group of populations by a very small involvement in the stand composition. Its proportion in a stand vary from 0.2 to $1.1 \%$ of forest areas within Russian regions (Martinsson and Lesinski, 2007), although this parameter increases towards the eastern race. Usually the race occurs in mixed stands of spruce (Picea obovata Ledeb.), birch (Betula spp.), aspen (Populus tremula L.), pine (Pinus sylvestris L.), etc. Unfortunately, information about genetic structure within the race is insufficient because the most of mtDNA markers already used on these territories were not polymorphic enough to reveal geographical structure on regional scale (Semerikov et al., 2013) and reference samples seem not be enough. 
The western macro-slope of the Urals (this mountain system extends to more than $2000 \mathrm{~km}$ as a border between Europe and Asia) is particularly interesting for research of gene pool of the western race of $L$. sibirica. Climatic and environmental factors change gradually in the East European and West Siberian plains. In comparison to this fact, a great variation of natural conditions exists in the Urals in climate, relief, soils, hydrologic features, etc. These factors, together with succession processes after last glaciation and human impact caused fragmentation, geographic isolation and small population sizes of larch stands. A role of the gene drift is more significant under such conditions in the formation of the gene pool and relatively irregular distribution of allele frequencies is expected. Indeed, it was revealed that the western race of $L$. sibirica has here the most genetically diverse populations according to phenotypic, karyological and isozyme data (Putenikhin et al., 2004). Population, associative and comparative genomic analysis of forest tree species under such conditions allows to single out the adaptive structure of populations, understand the molecular evolution and detect genes affected by various forms of selection (Krutovsky, 2006). Research on the state, reproduction and dynamics of the gene pool (as an important natural resource that determines the potential fitness of living organisms and, ultimately, their long-term survival) becomes an important scientific problem in the context of global climate change and increased anthropogenic environmental impact (Rellstab et al., 2016). The knowledge about patterns of local population differentiation of forest tree species are important to develop scientifically based forest protection, forest-seed and reforestation programs (Petit et al., 1998) which are necessary in forestry mostly on the local level.

Despite the potentially great scientific interest, investigations of the gene pool of larch populations in the region, based on new DNA techniques have not been carried out. Thus, the aim of this research is to identify patterns of genetic structure of populations and differentiation among them by using the analysis of nucleotide polymorphism.

\section{Materials and Methods}

\section{Population sampling and DNA extraction}

Material for the research was collected in 9 natural populations of the western race of Larix sibirica Ledeb. in the Northern and Middle Urals (Table 1). The samples were collected regarding the latitudinal gradient along the mountain system and altitudes of stands. Geographic distances between stands averaged $279 \pm 21 \mathrm{~km}$ and vary within 30-189 km (pairs Ls1/Ls2, Ls1/Ls3, Ls1/Ls4, Ls2/Ls3, Ls2/Ls4, Ls3/Ls4, Ls4/Ls5, Ls6/Ls7, Ls7/Ls8 and Ls8/Ls9), 189-349 km (Ls1/Ls5, Ls1/Ls6, Ls1/Ls7, Ls2/Ls5, Ls2/Ls6, Ls3/Ls5, Ls3/Ls6, Ls3/Ls7, Ls4/Ls6, Ls4/Ls7, Ls5/Ls7, Ls6/Ls8, Ls6/ $L s 9$ and $L s 7 / / s 9)$ and $349-508 \mathrm{~km}$ (other 12 pairs). The needle samples of the larch were taken in 270 adult trees (Table 1). Distances between neighboring trees were at least $50 \mathrm{~m}$ to reduce the effect of family clustering of individuals on the results.

The DNA isolation was carried out using the technique (Rogers, Bendich, 1985) modified by the addition of PVPP (polyvinylpolypyrrolidone) as a sorbent. The weight of the plant material per a tree was $20 \mathrm{mg}$. The concentration and spectral characteristics of DNA were examined on ${ }^{\circledR}$ NanoDrop2000 (Thermo scientific, USA). The DNA concentration of each sample was adjusted for PCR to $10 \mathrm{ng} / \mu \mathrm{L}$.

\section{DNA amplification and sequencing}

We studied three loci to analyze the population nucleotide polymorphism. The locus $A B A-W D S$ (it is designated as Locus 1) was sequenced for the first time in the genome of $L$. sibirica. The sequences of this locus were determined in Pseudotsuga menziesii var. menziesii and are represented on the GenBank NCBI (http://www.ncbi.nlm.nih.gov/) under the numbers AY832389 - AY832416. We also re-sequenced two loci, SSPCDFD040B03103 and 4CL1-363 (designated as Locus 2 and Locus 3, respectively), the sequences of which are presented in GenBank NCBI under the numbers KC213987 - KC214265 (Table 2). This allowed us to use for the analysis data on additional larch populations from another part of the species range (Semerikov et al., 2013). All the loci belong to the nuclear genome; they are parts of the protein coding genes. Locus 1 is a part of the gene ABA-WDS which encodes ABA-inducible dehydrin protein. Locus 2 (it belongs to the MADS-box transcription factor gene) encodes the DNA-binding MADS domain. Locus 3 belongs to the $4 C L$ gene, which encodes the enzyme 4-coumarate: CoA ligase (Dixon, 2010).

Table 1

Geographic coordinates, sample sizes and average number of analyzed sequences in L. sibirica populations

\begin{tabular}{|c|c|c|c|c|}
\hline $\begin{array}{l}\text { Abbrevi- } \\
\text { ation }\end{array}$ & Location & Coordinates & $\mathrm{N}_{1}$ & $\mathrm{~N}_{2}$ \\
\hline \multirow[t]{2}{*}{ Ls1 } & Perm region, Natural reserve & N 61.1130 & 30 & 20 \\
\hline & "Vishersky" & E 58.8899 & & \\
\hline \multirow[t]{2}{*}{ Ls2 } & Perm region, Natural reserve & N 61.1178 & 30 & 10 \\
\hline & "Vishersky" & E 59.1537 & & \\
\hline \multirow[t]{2}{*}{ Ls3 } & Perm region, & N 60.3264 & 30 & 8 \\
\hline & Krasnovishersk & E 57.0931 & & \\
\hline \multirow[t]{2}{*}{ Ls4 } & Perm region, & N 60.5147 & 30 & 18 \\
\hline & Cherdyn & E 55.9203 & & \\
\hline \multirow[t]{2}{*}{ Ls5 } & Perm region, & N 60.1739 & 30 & 16 \\
\hline & Gainy & E 53.6213 & & \\
\hline \multirow[t]{2}{*}{ Ls6 } & Sverdlovsk region, & N 58.7824 & 30 & 16 \\
\hline & Kachkanar & E 59.4068 & & \\
\hline \multirow[t]{2}{*}{ Ls7 } & Perm region, & N 58.2998 & 28 & 12 \\
\hline & Dobryanka & E 56.3664 & & \\
\hline \multirow[t]{2}{*}{ Ls8 } & Perm region, & N 57.0688 & 30 & 10 \\
\hline & Suksun & E 57.5653 & & \\
\hline \multirow[t]{2}{*}{ Ls9 } & Sverdlovsk region, & N 56.9499 & 30 & 16 \\
\hline & Pervouralsk & E 59.8483 & & \\
\hline
\end{tabular}


Amplification of Locus 1 was carried out as described in our previous studies (Nechaeva et al., 2017). For amplification of other two loci, the nested PCR method was used (Semerikov et al., 2013). The BigDye ${ }^{\circledast}$ Terminator v3.1 Cycle Sequencing Kit was used for the sequencing reaction. Product purification was carried out using the BigDye ${ }^{\circledast}$ XTerminatorTM Purification Kit (Applied Biosystems, USA). Capillary electrophoresis was performed on a Genetic Analyzer 3500xL (Applied Biosystems, USA) in two directions (forward and reverse). The editing of nucleotide sequences was carried out in SequenceScanner v2.0 (Applied Biosystems, USA). The location of the polymorphic positions was determined by multiple alignment in the Unipro UGENE v1.29 computer program (Okonechnikov et al., 2012) using the MAFFT algorithm(Katoh and Standley, 2013).

Table 2

Description of the analyzed loci

\begin{tabular}{lll}
\hline Loci & Product of gene, locus size & Source \\
\hline Locus 1 & $\begin{array}{l}\text { ABA-inducible protein (a part } \\
\text { of the gene), 344 bp }\end{array}$ & $\begin{array}{l}\text { Krutovsky and Neale, 2005; } \\
\text { Eckert et al., 2009, }\end{array}$ \\
Locus 2 & $\begin{array}{l}\text { MADS-box-transcription factor } \\
\text { (complete gene), 1518 bp }\end{array}$ & $\begin{array}{l}\text { Semerikov et al., 2013 } \\
\text { Locus 3 }\end{array}$ \\
$\begin{array}{l}\text { 4-kumarat: CoA ligase } \\
\text { (a part of the gene), 1236 bp }\end{array}$ & Semerikov et al., 2013 \\
\hline bp-base pairs
\end{tabular}

The data on sequenced locus sequences was compared to the existing sequences in the NCBI genetic database (National Center for Biotechnology Information, http://www.ncbi.com) using the automatic on-line alignment system BLAST+ v2.3.0 (Camcho et al., 2009). The structural analysis (analysis of the intron-exon structure) of the sequences was carried out in the DnaSP v6 program (Rozas et al., 2017). In this program, polymorphic sites were also analyzed, heterozygous positions were established and haplotypes were reconstructed in DnaSP v6 program (Rozas et al., 2017). Indels were not taken into account. The resulting nucleotide sequences of three loci of $L$. sibirica with a total length of 250.391 nucleotides (for all the trees studied) are included in the world genetic database of GenBank NCBI under the numbers: KT364889-KT365131.

\section{Data analysis}

The following nucleotide polymorphism indices were calculated based on the comparison of their nucleotide sequences: number of variable sites $(S)$, number of haplotypes in a population $\left(h_{n}\right)$, total haplotypic diversity $\left(H_{d}\right)$ (Nei, 1973), nucleotide diversity $(\pi)$, which estimates the average number of pair differences between two sequences per site, nucleotide diversity parameter calculated based on the number of mutations $\theta_{w}$ or the Watterson estimate (Nei, 1987). The Arlequin v3.5.2.2. program (Excoffier and Lischer, 2010) was used to calculate these parameters, as well as to estimate the haplotype diversity (average numbers pairwise differences between haplotype $-k$ ) and the fixation index $\left(F_{S T}\right)$, to analyze molecular variance (AMOVA). A cluster analysis was carried out using the
STRUCTURE v2.3.4 program (Hubisz et al., 2009). The number of clusters $(K)$ ranged from 1 to 12 . The program STRUCTURE Harvester (Earl, vonHoldt, 2012) was used to determine the most probable number of genetic groups based on the LnPD log likelihood by Evanno's methods (Evanno et al., 2005). This web-program allows detect the appropriate number of clusters by their individual search. Five analysis runs were performed, each included a data acquisition phase consisting of 100000 iterations. To visualize the results, the CLUMPAK (Kopelman et al., 2015) service was used. Principal Component Analysis is performed in PAST v3 program (Hammer et al., 2001). Program PopART v1.7 (Leigh, Bryant, 2015) was used to build haplotype networks.

\section{Results}

The characteristics of the sequences and nucleotide polymorphism

As a result of sequencing, 243 nucleotide sequences of three gene loci were obtained $(68,85,90$ sequences for loci 1, 2, and 3 , respectively). The total length of the sequences of the three loci of all individuals studied was 250391 nucleotides. The alignment length varies from 360 to 1395 bp (Table 1). Structural analysis of the sequences showed that the studied loci contained both coding and non-coding elements of the genes. About half of the analyzed sequence (55.2\%) was exons, and the rest was introns and non-coding elements (Table 3 ). Moreover, the largest number of polymorphic positions was found in non-coding parts of loci. Of all the substitutions in coding elements (exons), only $2.5 \%$ were non-synonymous (i.e., potentially exposed to natural selection). A total of 200 polymorphic positions were detected and analyzed in sequences of three loci. The smallest number of polymorphic positions was detected at locus 3, and the most polymorphic was locus 2, containing 133 substitutions and two deletions (Table 3).

The parameters of population genetic variability are presented in Table 4. The most part of populations are characterized by relatively high and comparatively similar genetic diversity with some exceptions (Ls8: $H d=0.636$; Ls7: $\pi=0.009$; $\left.\theta_{w}=0.012\right)$.

\section{The haplotype composition}

In total 27 haplotypes were detected in the Locus 1, with an average number of paired differences of $3.668 \pm 0.457$ (varies from 1 to 16). Haplotype aba-2 was found in all the populations. It unites $23.8 \%$ of all the sequences obtained. Locus 2 has 68 haplotypes, differing from 1 to 54 nucleotides $(0.71-3.87$ $\%)$. The average number of pair differences $(k)$ is $10.647 \pm 4.475$. Almost half ( $49 \%$ ) haplotypes were unique for a population. The most common haplotype sSPs-2 (it was found in eight of nine populations) combines $26.5 \%$ of all sequences. Thirty haplotypes were identified in the Locus 3. Differences between them vary from 1 to 8 nucleotides $(0.09-0.72 \%)$. The average number of pair differences was $2.317 \pm 0.563$. The most part of haplotypes (18 or $60 \%$ ) were unique. Haplotype Hap-3 is found in all the stands and it unites $23.8 \%$ of the sequences. Some 
populations were characterized by especially high haplotypic diversity (Table 5: the highest values of the parameters in a population are in bold).

Table 3

Structural elements of three loci of $L$. sibirica populations

\begin{tabular}{lllll}
\hline $\begin{array}{l}\text { Structural element, } \\
\text { bp/locus }\end{array}$ & Locus 1 & Locus 2 & Locus 3 & In total \\
\hline Exons & 360 & 195 & 1028 & 1583 \\
Introns and non-coding & - & 1200 & 82 & 1282 \\
Total length & 360 & 1395 & 1110 & 2865 \\
\hline Bp - length oft he locus tructural elemt in base pairs
\end{tabular}

Table 4

Genetic diversity of $L$. sibirica populations for three studied loci

\begin{tabular}{lccc}
\hline Population & $H d \pm s d$ & $\pi \pm s d$ & $\theta_{w}$ \\
\hline Ls1 & $0.872 \pm 0.020$ & $0.006 \pm 0.002$ & 0.006 \\
Ls2 & $0.871 \pm 0.039$ & $0.006 \pm 0.002$ & 0.006 \\
Ls3 & $0.887 \pm 0.003$ & $0.006 \pm 0.002$ & 0.006 \\
Ls4 & $0.857 \pm 0.038$ & $0.005 \pm 0.002$ & 0.005 \\
Ls5 & $0.836 \pm 0.077$ & $0.006 \pm 0.001$ & 0.007 \\
Ls6 & $0.859 \pm 0.016$ & $0.007 \pm 0.002$ & 0.006 \\
Ls7 & $0.883 \pm 0.030$ & $0.009 \pm 0.003$ & 0.012 \\
Ls8 & $0.636 \pm 0.059$ & $0.006 \pm 0.002$ & 0.008 \\
Ls9 & $0.911 \pm 0.011$ & $0.007 \pm 0.002$ & 0.007 \\
Pooled sample & $0.896 \pm 0.010$ & $0.007 \pm 0.002$ & 0.015 \\
\hline Hd - total haplotypic diversity; $\pi-$ nucleotide diversity, $\theta_{w}-$ nucleotide diversity \\
parameter calculated based on the number of mutations; sd-standard devia- \\
tion
\end{tabular}

According to previous our studies (Nechaeva et al., 2017), Locus 3 among the three studied loci has the most selectively neutral polymorphism, so a median haplotype network has been shown on Figure 1 as an example of identification of links between haplotypes. Some dominant haplotypes are well traced in their median network (see an example of Hap-1, Hap-3 and Hap-9 of Locus 3). They combine the majority of populations that form stellate structures indicating the common origin of the constituent haplotypes. At the same time, the common haplotypes occupy both central and distal positions on branches, and the presence of possible alternative links does not allow establish any unequivocal relationship between haplotypes. This structure of the median network suggests that a part of the populations studied previously forms a single large population. The genetic structure of the distribution of haplotypes noted on the median network of haplotypes is well traced on the topology of the distribution of haplotypes in geographic space (Figure 2). It is noticeable that the spatial distribution of haplotypes and haplotypic network does not show consistency with the location of trees that bear these haplotypes. At the same time, attention is drawn to the fact that the most numerous haplotype Hap-3, which unites all populations, is practically absent in the sample Ls8. This population is characterized by the smallest haplotypic diversity with a predominance of Hap-9. This haplotype is relatively rare for other populations and almost absent in the next sample Ls9. Interesting enough are differences in the composition of haplotypes of Ls1 and Ls2, separated only by a distance of about 30 $\mathrm{km}$ and locating on the neighboring ridges of the Urals. The median networks of the othertwo loci also have a similar complex branched structure with several dominant haplotypes, and haplotypes that differ in several mutational positions. Such picture is characteristic for populations that existed for a long time in a sufficiently high abundance in the non-isolated environment (Svetlakova et al., 2014).

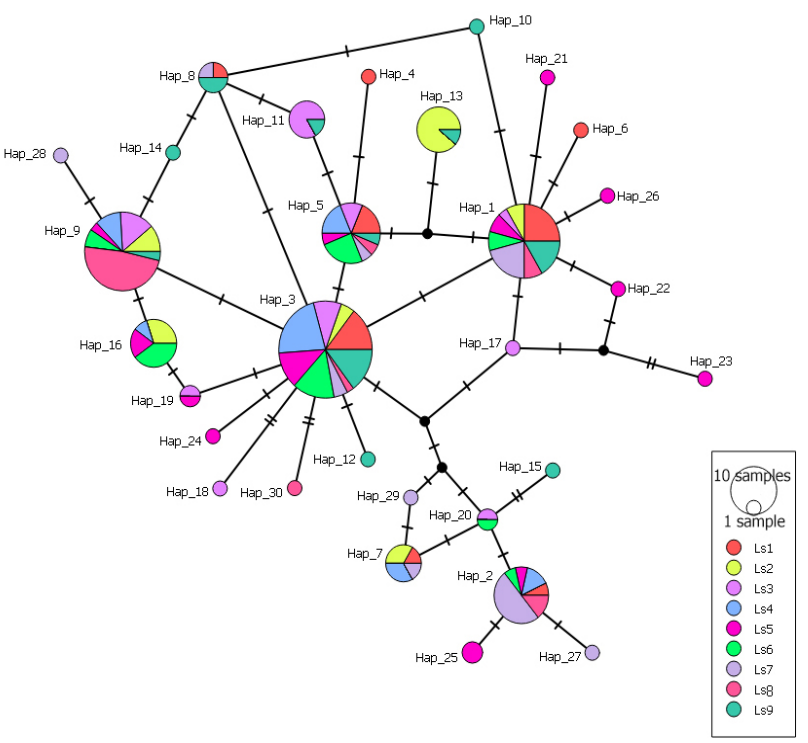

Figure 1

Median network of the haplotypes of Locus 3. Circles represent individual haplotypes, the diameter of a circle corresponds to the number of samples with the haplotype and reflects its approximate frequency. The length of the branches corresponds to the number of mutations between haplotypes. Cross lines denote the number of mutations between individual haplotypes. 


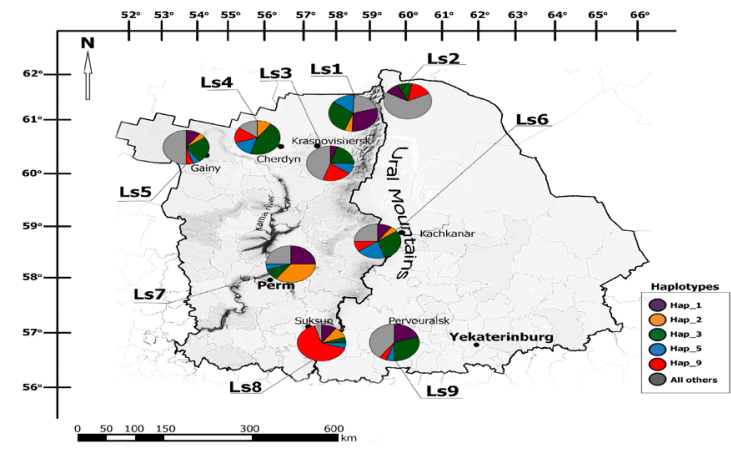

Figure 2

Spatial distribution of haplotypes in the populations of $L$. sibirica.

Table 5

The number of haplotypes $\left(h_{n}\right)$ and average number of pairwise differences between haplotypes $(k)$ of $L$. sibirica populations

\begin{tabular}{lcccccc}
\hline Populations & \multicolumn{2}{c}{ Locus 1 } & \multicolumn{2}{c}{ Locus 2 } & \multicolumn{2}{c}{ Locus 3 } \\
\hline & $h_{n}$ & $k$ & $h_{n}$ & $k$ & $h_{n}$ & $k$ \\
Ls1 & 9 & 3.34 & 12 & 9.97 & 8 & 1.88 \\
Ls2 & 5 & 4.49 & 14 & 6.84 & 6 & 3.00 \\
Ls3 & 5 & 3.25 & 11 & 10.69 & 9 & 2.09 \\
Ls4 & 7 & 3.27 & 12 & 7.29 & 6 & 2.07 \\
Ls5 & 5 & 3.20 & 8 & 9.23 & 13 & 2.98 \\
Ls6 & 8 & 3.77 & 11 & 11.62 & 7 & 1.93 \\
Ls7 & 6 & 4.12 & 14 & 21.09 & 9 & 3.16 \\
Ls8 & 5 & 3.96 & 6 & 6.43 & 6 & 1.73 \\
Ls9 & 10 & 3.62 & 13 & 12.66 & 11 & 1.99 \\
Average & 6.7 & 3.67 & 11.2 & 10.65 & 8.3 & 2.32 \\
\hline
\end{tabular}

\section{The genetic differentiation}

According to the results of the AMOVA analysis of all three loci, the bulk of the entire genetic variability $(91.4 \%)$ account for its within-population component $\left(F_{S T}=0.086, \mathrm{p}<0.001\right)$. This index for each of three loci varies from 0.050 (Locus 1) to 0.101 (Locus 3) and 0.160 (Locus 2). $F_{S T}$ values vary significantly between pairs of populations (Table 6). Locus 2 contributes the largest part to the differentiation among populations. The parameter ranges from -0.001 to 0.487 . In general population pairs had statistically relevant differences $(p<0.050)$ in values of $F_{S T}$ Locus 1 has a relatively small contribution to differences between populations $\left(F_{S T}=-0.002-0.144\right)$. Significant differences are found only in a few pairs and almost exclusively with participation of Ls7. The pairwise values of $F_{S T}$ in Locus 3 change from -0.001 up to 0.250 . Significant differences were revealed between many pairs of populations. Ls7, Ls8 and Ls2 differ from other stands on the highest level. Relatively high values of the fixation index are also revealed between the pair Ls7 and Ls8. According to our previous studies (Nechaeva et al., 2017), Locus 3 has the most selectively neutral polymorphism among the studied loci. Therefore, its $F_{S T}$ values (Table 6) can more correctly reflects the gene flow between populations. It is noteworthy that the differentiation of populations at this locus is expressed at much higher levels of significance in comparison to all the loci. When using $F_{S T}$ values, the Principal Component Analysis demonstrated unevenly distribution of populations (Figure 3). Samples Ls2, Ls5, Ls7 and Ls8 were significantly differentiated from the others independently on a locus studied.

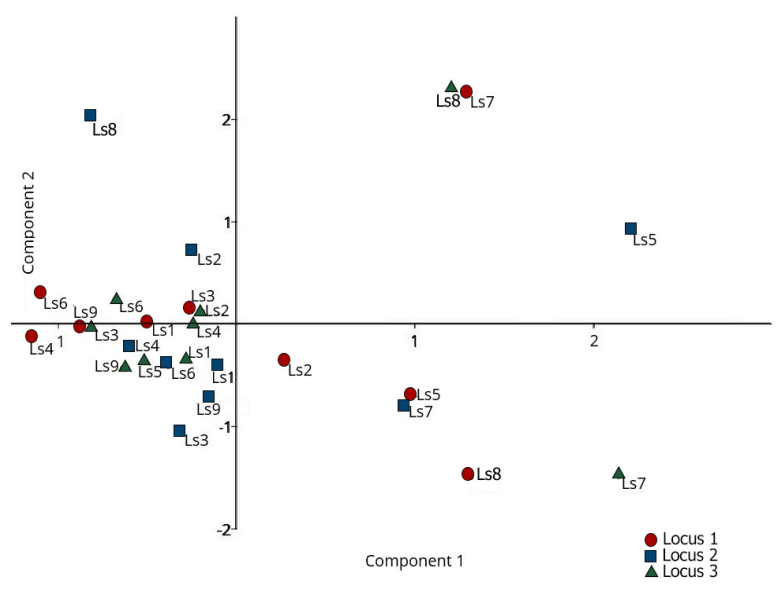

Figure 3

Results of the Principal Component Analysis using the $F_{\text {st }}$ values in three loci of $L$. sibirica.

The analysis of the population structure using the STRUCTURE program (Figure 4) was carried out to determine the optimal number of genetic clusters. It is established that the most probable is the structure that is detected at $K=4$. Evanno analysis using the $L n P D$ logarithm of the likelihood revealed that the average value of the logarithm of the probability function $L n P$ $(D)$ increases from $\mathrm{K}=2$ to $\mathrm{K}=4$, and then decreases sharply; the dispersion also increases significantly. The maximum value of $\operatorname{LnP}(D)$ with low dispersion is observed at $K=4$. The value of the DeltaK coefficient is also maximal at $K=4$. The genotypic profiles of most samples are characterized by a mixed structure, with the exception of Ls2 and Ls8 (Figure 4), which contain haplotypes that are rare in other populations; these populations also show comparatively large pairwise $F_{s t}$ values.

To determine the relation of the population genetic structure with the geographical location of the stands, the correlation analysis (Mantel's test) was carried out on the base $F_{S T}$. The analysis on three loci indicates the absence of a correlation between these parameters. However, the analysis of the most selectively neutral Locus 3 revealed a weak correlation ( $r=$ $0.158, p=0.010$ ). When most genetically differentiated populations (Ls7 and Ls8) were excluded from the analysis, a more significant positive correlation was revealed $(r=0.282, p=0.060)$. This parameter reaches the largest value $(r=0.761, p=0.040)$ when analyzing populations (Ls1, Ls2, Ls6, Ls9) located along the ridges of the Ural Mountains. 
Table 6

Pairwise $F_{S T}$ values for all the loci (below the diagonal) and Locus 3 (above the diagonal)

\begin{tabular}{|c|c|c|c|c|c|c|c|c|c|}
\hline Populations & Ls1 & Ls2 & Ls3 & Ls4 & Ls5 & Ls6 & Ls7 & Ls8 & Ls9 \\
\hline Ls1 & & $0.079^{*}$ & 0.040 & 0.055 & 0.022 & 0.053 & $0.160^{* * *}$ & $0.194^{* * *}$ & -0.008 \\
\hline Ls2 & $0.127^{* * *}$ & & $0.104^{* *}$ & $0.131^{* *}$ & $0.086^{*}$ & $0.094^{*}$ & $0.198^{* * *}$ & $0.164^{* * *}$ & $0.090^{* *}$ \\
\hline Ls3 & $0.063^{* *}$ & $0.108^{* * *}$ & & 0.041 & $0.074^{*}$ & 0.022 & $0.212^{* * *}$ & $0.126^{* * *}$ & -0.001 \\
\hline Ls4 & 0.042 & $0.140^{* * *}$ & 0.048 & & 0.022 & -0.014 & $0.095^{*}$ & $0.084^{*}$ & $0.077^{*}$ \\
\hline Ls5 & 0.007 & $0.078^{* * *}$ & 0.024 & 0.014 & & 0.009 & 0.070 & $0.104^{* * *}$ & 0.050 \\
\hline Ls6 & 0.012 & $0.097^{* * *}$ & 0.030 & -0.001 & -0.020 & & $0.153^{* * *}$ & 0.042 & $0.060^{*}$ \\
\hline Ls7 & 0.017 & $0.131^{* * *}$ & $0.084^{* *}$ & $0.106^{* *}$ & 0.013 & $0.080^{* *}$ & & $0.250^{* * *}$ & $0.207^{*}$ \\
\hline Ls8 & $0.254^{* * *}$ & $0.220^{* * *}$ & $0.142^{* * *}$ & $0.218^{* * *}$ & $0.194 * * *$ & $0.214^{* * *}$ & $0.260^{* * *}$ & & $0.160^{* * *}$ \\
\hline Ls9 & -0.021 & $0.084^{* * *}$ & 0.023 & 0.028 & -0.009 & 0.007 & 0.028 & $0.213^{* * *}$ & \\
\hline
\end{tabular}
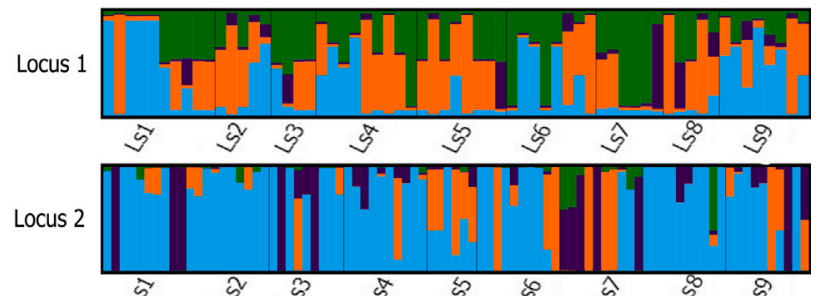

Locus 3

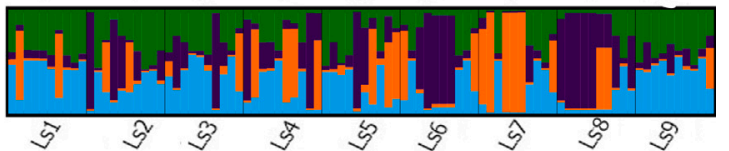

All loci

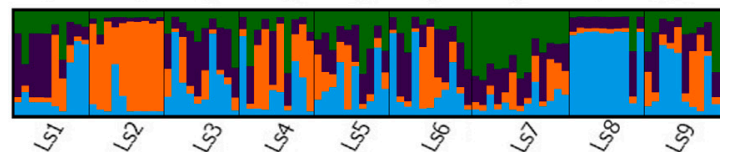

Figure 4

Results of the analysis of the structure of $L$. sibirica populations using the STRUCTURE v. 2.3 program (the number of clusters $\mathrm{K}=4$ ).

We additionally analyzed the nucleotide sequence of the Locus 3 (4CL1-363) in other L. sibirica populations (Semerikov et al., 2013) by using the genetic database of the GenBank NCBI. Thus, we added to the analysis a set of eight populations of the species' western race (Figure 5). They are located on the northern and southern parts of area of distribution of the race, including the eastern macro-slope of the Middle Urals. When studying the correlation of genetic and geographical distances, no significant correlation was found $(r=0.001, p=0.480$ at three loci and $r=0.158, p=0.010$ for Locus 3). About $30 \%$ (11 of 37) of revealed haplotypes were found to be common in these populations of $L$. sibirica in the Western Siberia, and 19 haplotypes (51\%) were identified only in our study. Hap-7 is represented in four populations (Ls1, Ls2, Ls4, Ls7), Hap-13 in two populations (Ls2 and Ls9), the rest are singularly present in all populations except Ls6. The joint median network reveals again the same haplotype structure of Locus 3 with dominant haplotypes forming stellate structures and apparently ancestral for the entire population. At the same time, they have a large share in comparison with the populations of $L$. sibirica in the
Western Siberia (Figure 5). It is noticeable that some of the haplotypes found in this study have a higher frequency of occurrence than in populations previously studied (Semerikov et al., 2013), for example, Hap-7 and Hap-13.

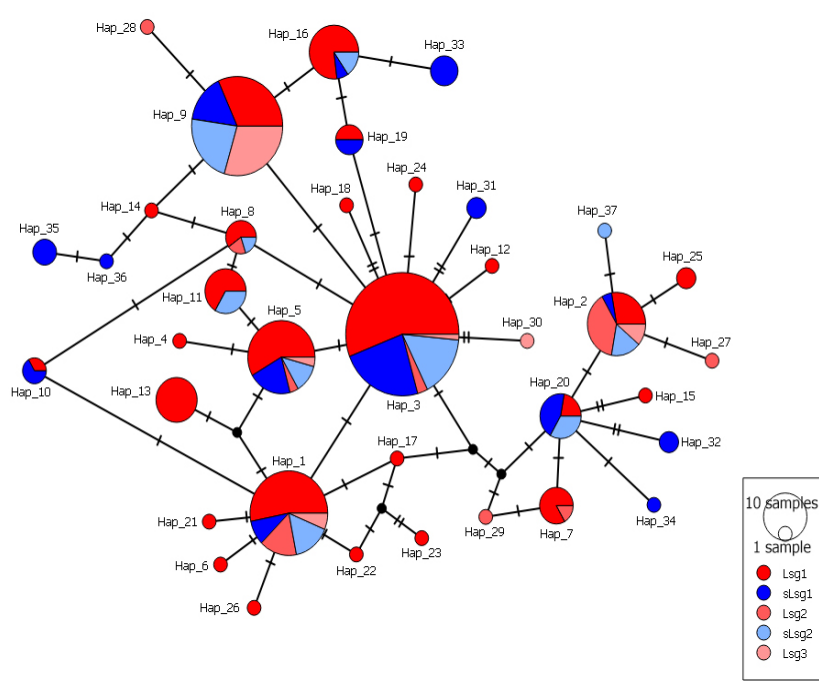

Figure 5

Median network of the haplotypes of Locus 3. Samples of this study are indicated by red shades, blue shades represent samples of L. sibirica of the Western Siberia (Semerikov et al., 2013). Others comments are given in Figure 1.

\section{Discussion}

Relatively high nucleotide diversity of the western race of $L$. sibirica of the Middle and Northern Urals was established in this study. This result is confirmed by results of morphological and allozyme investigations (Putenikhin et al., 2004). They have been allowed to identify so called "Perm-Kama pre-Urals" larch populations with the highest level of variation in Urals. The polymorphism of larch populations of the Middle and Northern Urals $\left(H d=0.846 \pm 0.027 ; \pi=0.0064 \pm 0.0004 ; \theta_{w}=0.0070\right.$ 
$\pm 0.0007)$ are higher of values typical for other parts of the species area of distribution. For example, total haplotype and nucleotide diversities for 8 candidate genes in 11 populations of the both races of $L$. sibirica were $H d=0.822 ; \pi=0.0054$ and $\theta_{w}=$ 0.0067 (Semerikov et al., 2013).

Differences between populations within the studied relatively small region are more pronounced in these parameters $\left(H d=0.636-0.911 ; \pi=0.0050-0.0090 ; \theta_{w}=0.0050-0.0120\right)$ than in other parts of the range of the western race of Siberian larch. A confirmation of this result is the study of $L$. sukaczewii (Araki et al., 2008) where much lower variations of the parameter were revealed in all other parts of the taxon area of distribution $\left(\pi=0.0020-0.0033, \theta_{w}=0.0026-0.0027\right.$ and $\pi=0.0033$, $\theta_{w}=0.0027$ for the regions of ITS and $4 C L$ genes, respectively). It is possible that the increased genetic diversity of some populations is a consequence of the influence of larch glacial refuges in the Urals (Semerikov and Lascoux, 2003).

The magnitude of the differentiation between pairs of populations in our study $\left(F_{S T}=-0.021-0.260\right)$ is also larger than the limits of pairwise values of the parameter between other larch populations of the western race. So $F_{S T}$ values of populations of L. sukaczewii varies from -0.078 to 0.115 (Araki et al., 2008) despite of the much greater distances between pairs of them (according to coordinates of populations in the paper the distances are from 516 to $1346 \mathrm{~km}$ ). Extremely low differences are found in this study between four stands from all the European part of Russia and the north of the West Siberian Lowland $\left(F_{S T}=-0.078-0.008\right.$ and $F_{S T}=-0.069-0.008$ for ITS and $4 C L$ genes, respectively). But $F_{S T}$ values reaches higher levels when we include a population from the Urals into pairwise comparisons $\left(F_{S T}=-0.001-0.115\right.$ and $\left.F_{S T}=0.087-0.238\right)$. These data confirm our results that the race on the Urals has got a relatively high level of differentiation among populations.

Population-genetic studies of Eurasian larch species has been allowed us to establish the uneven spatial distribution of the genetic diversity. Zones with a relatively homogeneous geographic distribution of mitochondrial haplotypes of the Siberian larch were determined although somewhere their distribution can be described in the term of "spatial mosaicism" (Semerikov et al., 2007). Using restriction-site associated DNA (RAD) sequencing, recently a set of newly developed 253 SNP loci of Larix spp. was screened on 916 individuals of 52 populations in Russia (Blanc-Jolivet et al., 2018). Well-defined genetic clusters on the East-West transect from the Far East to the Urals were revealed with especially high genetic diversity on borders of the species. Various chloroplast (SSRs, PCR-RFLP), mitochondrial and nuclear markers (isozymes, DNA sequences, AFLP, SSRs) have been demonstrated clearly localized such contact zones among Russian larch species (Semerikov and Lascoux, 1999, 2003; Semerikov et al., 2007, 2013; Araki et al., 2008; Khatab et al., 2008; Polezhaeva et al., 2010; Oreshkova et al., 2013). It is possible that the Middle and Northern Urals are such part of the larch area of distribution, where the gene pool of populations is formed under the influence of both races of $L$. sibirica.

Migration of the larch from the Southern Urals Pleistocene refuges to eastern populations can explain these regularities.
The study of the genetic structure of $L$. sibirica populations from the western (this study) and the eastern parts of the range (Semerikov et al., 2013) did not reveal the relative contribution of the genes of the eastern populations and also points to the isolation of the genotypic composition Ls1 and Ls8 (Figure 6). On the contrary it is suggested (Araki et al., 2008) that the larch of the Eastern European Plain spread also from second refuge, not only from the Southern Urals.

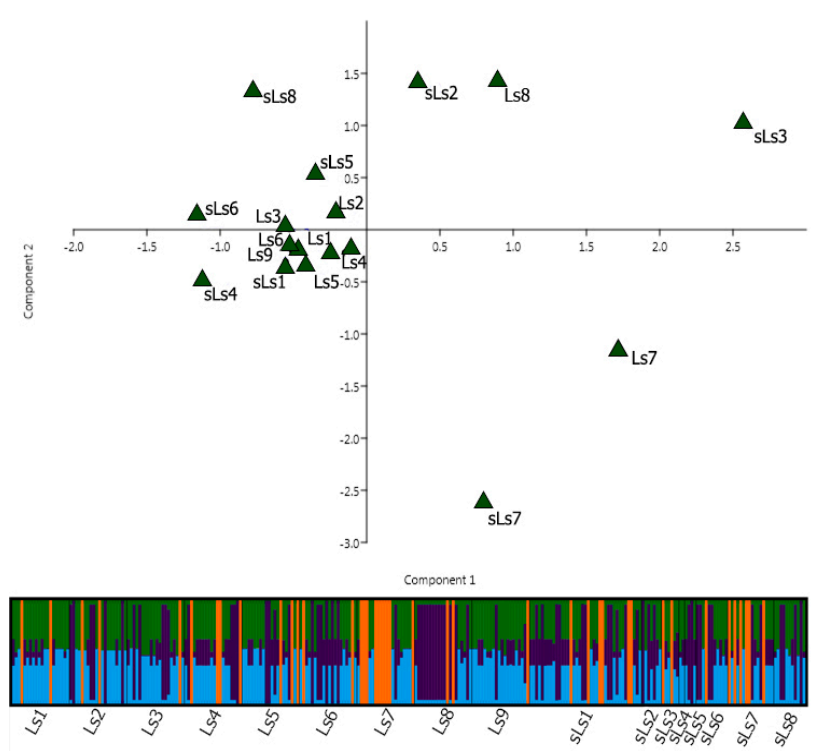

Figure 6

Results of the analysis of main components using the $F_{\text {st }}$ values in Locus 3 (the upper part of the figure). Results of the analysis of the structure of $L$. sibirica populations at Locus 3 using the STRUCTURE program v. 2.3 (the number of clusters $K=4$ ) are given below. Ls1 - Ls9 represent populations of this study, and SLs1 - sLs8 are samples of L. sibirica of the Western Siberia (Semerikov et al., 2013).

Our previous studies indicate that in different large geomorphological formations of the Urals the genetic structuring of populations occur in different ways. Thus, while studying PopuIus tremila L. populations in the same region, it was established that the genetic structure in the mixed coniferous-broadleaved forests is formed by the type of "isolation by distance" (Svetlakova et al., 2014) in comparison to the mountainous dark coniferous taiga where genetic spatial mosaicism is a common pattern. While studying the L. sibirica of the Urals by using ISSR-analysis (Nechaeva et al., 2014), significant correlations of the genetic parameters within groups of mountain and plain populations with geographical distances $(r=0.680, p=$ 0.023 and $r=0.760, p=0.020$, respectively) and altitudes of stands above sea level $(r=0.940, p=0.020)$. This is consistent with the data of this study, because a significant correlation was detected in the group of mountain populations $(r=0.761$, 
$p=0.040$ ). But these patterns disappear in a combined analysis of all the larch populations. A likely cause is the lack of relations between some larch forests within the region. It is known (Svetlakova et al., 2014) that natural or artificial forest fragmentation can lead to genetic changes on the population level. As it was mentioned above, according to the data of the longterm research in the Urals (Putenikhin et al., 2004), the fragmentation of larch stands is clearly expressed on the Urals. The revealed differentiation among populations changed from moderate to high values with participation of more or less significant geographically isolated Ls7, Ls8 and Ls2 in pair population comparisons. Ls8 characterizes a population of the western macro-slope of the Ural Mountains located almost in the center of the "non-larch tongue" (Dylis, 1947). Ls7 is located in a district with a high intensity of economic activity for many centuries. According to the previous our studies (Nechaeva et al., 2014) this population has an altered genetic structure. One of the most obvious reason that cause this degradation of the stand is the partial logging.

Thus, the analysis of the nucleotide DNA polymorphism made it possible to reveal a high level of genetic diversity of $L$. sibirica in the Middle and Northern Urals within and among populations. The obtained data in general are confirmed by the results of studies that were conducted out using other tools, methods and approaches. The uniqueness and diversity of the Urals geomorphological formations, past events in the forest history and anthropogenic influences can determine the regional genetic structure patterns. The revealed larch forests with a unique gene pool and/or high genetic diversity should be objects of population-oriented forestry and conservation.

The reported study was partially supported by the Government of Perm Krai, research project C-26/174.3 31.01.2019.

\section{References}

Araki NHT, Khatab IA, G KK, Hemamali U, Inomata N, X.-R. Wang N X-R. and Szmidt AE (2008) Phylogeography of Larix sukaczewii Dyl. and Larix sibirica L. inferred from nucleotide variation of nuclear genes. Tree Genetics \& Genomes: 4 (4): 611-623. https://doi.org/10.1007/s11295-008-0137-1

Blanc-Jolivet C., Yanbaev Y, Kersten B, Degen B (2018) A set of SNP markers for timber tracking of Larix spp. in Europe and Russia. Forestry 91 (5): 614-628. https://doi.org/10.1093/forestry/cpy020

Dylis NV (1947) Siberian Larch. Moscow, Moscow Society of Naturalists (in Russian).

Dixon DP, Skipsey M and Edwards R (2010) Roles for glutathione transferases in plant secondary metabolism. Phytochemistry 71 (№ 4): 338-350. https://doi.org/10.1016/j.phytochem.2009.12.012

Earl DA and vonHoldt BM (2012) STRUCTURE: a website and program for visualizing STRUCTURE output and implementing the Evanno method. Conservation Genetics Resources. 4 (2): 359-361. https://doi.org/10.1007/s12686-011-9548-7

Eckert AJ, Wegrzyn JL, Pande B, Jermstad KD, Lee JM, Liechty JD, Tearse BR, Krutovsky KV and Neale DB (2009) Multilocus patterns of nucleotide diversity and divergence reveal positive selection at candidate genes related to cold hardiness in coastal Douglas Fir (Pseudotsuga menziesii var. menziesii). Genetics 183 (1): 289-298. https://doi.org/10.1534/genetics.109.103895

Evanno G, Regnaut S and Goudet J (2005) Detecting the number of clusters of individuals using the software structure: a simulation study. Molecular Ecology 14 (8): 2611-2620. https://doi.org/10.1111/j.1365-294x.2005.02553.x
Excoffier L and Lischer HEL (2010) Arlequin suite ver 3.5: A new series of programs to perform population genetics analyses under Linux and Windows. Molecular Ecology Resources 10 (3): 564-567. https://doi.org/10.1111/j.1755-0998.2010.02847.x

Hammer $\varnothing$, Harper DAT and Ryan PD (2001) PAST: Paleontological statistics soft ware package for education and data analysis. Palaeontologia Electronica 4: 1 - 9 .

Hubisz MJ, Falush D, Stephens M and Pritchard JK (2009) Inferring weak population structure with the assistance of sample group information. Molecular Ecology Resources 9 (5): 1322-1332. https://doi.org/10.1111/j.1755-0998.2009.02591.x

Katoh K, and Standley DM (2013) MAFFT Multiple Sequence Alignment Software version 7: improvements in performance and usability. Molecular Biology and Evolution 30 (4): 772-780. https://doi.org/10.1093/molbev/mst010

Khatab IA, Ishiyama H, Inomata N, Wang X-R and Szmidt AE (2008) Phylogeography of Eurasian Larix species inferred from nucleotide variation in two nuclear genes. Genes \& Genetic Systems 83 (1): 55-66.

https://doi.org/10.1266/ggs.83.55

Kopelman NM, Mayzel J, Jakobsson M, Rosenberg NA and Mayrose I (2015) CLUMPAK: a program for identifying clustering modes and packaging population structure inferences across K. Molecular Ecology Resources 15 (5): 1179-1191. https://doi.org/10.1111/1755-0998.12387

Krutovsky KV (2006) From population genetics to population genomics of fores trees: Integrated population genomics approach. Russian Journal of Genetics 42 (10): 1088-1100. https://doi.org/10.1134/s1022795406100024

Krutovsky KV and Neale DB (2005) Forest genomics and new molecular genetic approaches to measuring and conserving adaptive genetic diversity in forest trees. In: Conservation and Management of Forest Genetic Resources in Europe. Arbora Publishers, Zvolen Geburek. (Eds. Th. Geburek and J. Turok). pp: 369-390.

Leigh JW and Bryant D (2015) PopART: full-feature software for haplotype network construction. Methods in Ecology and Evolution 6 (9): 1110-1116. https://doi.org/10.1111/2041-210x.12410

Martinsson O and Lesinski J (2007) Siberian larch forestry and timber in a Scandinavian perspective. JiLU Jämtlands County Council Institute of Rural Development. Prinfo Accidenstryckeriet.

Nechaeva YuS, Boronnikova SV, Prishnivskaya YaV, Chumak El and Yusupov RR (2014) Analysis of ISSR-PCR polymorphism of markers and genetic structure of some populations of Siberian larch in the Urals. Modern problems of science and education 10 (6) (in Russian).

Nechaeva YuS, Julanov AA, Boronnikova SV and Prishnivskaya YaV (2017) Nucleotide polymorphisms of candidate genes of adaptive significance in the Ural populations of Larix sibirica Ledeb. Russian Journal of Genetics 53 (5): 587-595. https://doi.org/10.1134/s1022795417050064

Nei M (1973) Analysis of gene diversity in subdivided populations. Proceedings of the National Academy of Sciences of the USE 70 (12): 3321-3323. https://doi.org/10.1073/pnas.70.12.3321

Nei, M (1987) Molecular evolutionary genetics. New York: Columbia University Press. https://doi.org/10.1016/0047-2484(89)90093-6

Okonechnikov K, Golosova O and Fursov M (2012) Unipro UGENE: a unified bioinformatics toolkit. Bioinformatics 28 (8): 1166-1167. https://doi.org/10.1093/bioinformatics/bts091

Oreshkova NV, Belokon MM and Jamiyansuren S (2013) Genetic diversity, population structure, and differentiation of Siberian larch, Gmelin larch, and Cajander larch on SSR-marker data. Russian Journal of Genetics 49 (2): 178 186. https://doi.org/10.1134/s1022795412120095

Petit R.J, El Mousadik A and Pons O (2008) Identifying populations for conservation on the basis of genetic markers. Conservation Biology 12 (4): 844-855. https://doi.org/10.1111/j.1523-1739.1998.96489.x

Polezhaeva MA, Lascoux M and Semerikov VL (2010) Cytoplasmic DNA variation and biogeography of Larix Mill. in Northeast Asia. Molecular ecology 19 (6): 1239-1252. https://doi.org/10.1111/j.1365-294x.2010.04552.x

Putenikhin VP, Farukshina GG and Shigapov ZKh (2004) Larix Sukaczewii in the Urals: variability and population-genetic structure. Nauka, Moscow (in Russian).

Rellstab C, Zoller S, Walthert L, Lesur I, Pluess AR, Graff R, Bodenez C, Sperisen C, Kremer A and Gugerli F (2016) Signatures of local adaptation in candidate genes of oaks (Quercus spp.) with respect to present and future climatic 
conditions. Molecular Ecology 25 (23): 5907-5924.

https://doi.org/10.1111/mec.13889

Rogers SO and Bendich AJ (1985) Extraction of DNA from milligram amounts of

fresh, herbarium and mummified plant tissues. Plant Molecular Biology 5

(2): 69-76. https://doi.org/10.1007/bf00020088

Rozas J, Ferrer-Mata A, Sanchez-DelBarrio JC, Guirao S, Librado P, Ramos-Onsins SE and Sanches-Gracia A (2017) DnaSP 6: DNA sequence polymorphism analysis of large data sets. Molecular Biology and Evolution 34 (12): 3299 3302. https://doi.org/10.1093/molbev/msx248

Semerikov VL and Lascoux M (2003) Nuclear and cytoplasmic variation within and between Eurasian Larix (Pinaceae) species. American Journal of Botany 90 (8): 1113-1123. https://doi.org/10.3732/ajb.90.8.1113

Semerikov VL, Iroshnikov Al and Lascoux M (2007) Mitochondrial DNA variation pattern and postglacial history of the Siberian larch (Larix sibirica Ledeb.). Russian Journal of Ecology 38 (3): 147-154. https://doi.org/10.1134/s1067413607030010

Semerikov VL, Semerikova SA and Polezhaeva MA (2013) Nucleotide diversity and linkage disequilibrium of adaptive significant genes in Larix (Pinaceae). Russian Journal of Genetics 49 (9): 915-923. https://doi.org/10.1134/s102279541309007x

Svetlakova TN, Boronnikova SV and Yanbaev YuA (2014) Genetic diversity and differentiation in Ural populations of the aspen, Populus tremula L., as revealed by inter-simply sequence repeat (ISSR) markers. Silvae Genetica 63 (1-6): 39-41. https://doi.org/10.1515/sg-2014-0006 